and co-founder of the 720-million-yuan (US\$106-million) centre. His group was the first to clone primates, two identical macaque monkeys, last year. Other groups have edited the genomes of monkeys to create models of diseases, such as Huntington's disease and immune disorders.

But primates are expensive, and many people object to their use in research. The advantage of creating cloned monkeys is that it reduces the number of animals needed for certain types of experiment, such as testing whether a drug works, says Poo. Researchers typically need large numbers of animals to determine whether the effects they see are because of the drug or due to genetic variation between the animals. By using genetically identical animals, such uncertainty can be eliminated, reducing the number of animals required, he says.

Poo is planning to first create models of brain diseases, such as Alzheimer's disease and Parkinson's disease, followed, over the next few years, by primate models of metabolic and immune-deficiency disorders and cancer that scientists could use in research in China.

In Europe and the United States, research using non-human primates increasingly faces regulatory hurdles, high costs and bioethical opposition. This stands in contrast to Chinese research; the country's 2011 five-year plan set primate disease models as a national goal, and in 2014, the science ministry invested

25 million yuan in the endeavour.

But the process of cloning monkeys is inefficient and expensive. To create the 5 cloned macaques, the team started with 325 cloned gene-edited embryos, which it implanted into 65 surrogate monkeys. The process cost about $\$ 500,000$, estimates Poo.

The team used the standard cloning technique: DNA from a donor cell - in this case taken from an adult monkey with an edited

"Monkey
models would
be incredibly
helpful to allow
humanity to
treat or cure
these illnesses."
genome - is injected into an egg that has had its own genetic material removed. The DNA reprograms into an embryonic state, allowing specialized cells to form.

Poo's team is the first to clone primates using DNA from adult cells. The two macaques the group cloned last year came from fetal DNA. The success with adult DNA means that the group can check whether gene edits made to an embryo produce desirable traits in an adult monkey before scientists clone it.

That monkeys can be cloned from other living monkeys is an exciting proof of principle, says reproductive biologist Shoukhrat Mitalipov, from the Oregon Health and Sciences University in Portland. Mitalipov expects that the costs of cloning primates will come down, and that the animals will probably be a good model for researchers to study genetic diseases.

But some scientists think that experiments using monkeys should be a last resort because of the animals' high levels of cognition. Lazar says that some experiments for example, research into the genes behind human diseases - "are equally appropriate scientifically" in mice. Research in mice is also cheaper and more accepted by the public. Lazar worries that if scientists have ready access to gene-edited monkeys, they might use them for experiments that are conventionally done in rodents. Poo says that mice are not a good substitute for studying higher cognitive functions and brain disorders in humans. The ION follows strict international guidelines for animal research, he says.

Poo's team will continue to study the effect of gene editing on the five cloned macaques. The group disabled BMAL1, a gene that helps to maintain circadian rhythm, the internal clock that facilitates a healthy sleep-wake cycle, and found that the monkeys moved more at night and slept less overall, signs of circadianrhythm disorders.

The research was published in National Science Review, for which Poo is executive editor-in-chief. Poo says he did this because the journal needs publicity. But he says the papers were reviewed by international experts and he was not involved in their processing. -

\title{
Berkeley bans new research funding from Huawei
}

\section{Moratorium comes after United States charges Chinese firm with stealing trade secrets.}

\section{BY ELIZABETH GIBNEY}

$\mathrm{T}$ The University of California, Berkeley, will not enter into new research collaborations with the Chinese telecommunications firm Huawei, after the US Department of Justice brought criminal charges against the company on 28 January.

The University of Texas at Austin has also confirmed to Nature that it is reviewing its relationship with the company - which is a major investor in research worldwide.

The move comes two weeks after the University of Oxford, UK, said that it would stop seeking new funding from the firm, citing "public concerns raised in recent months surrounding UK partnerships".

Since late 2018, Huawei - a major electronics manufacturer headquartered in

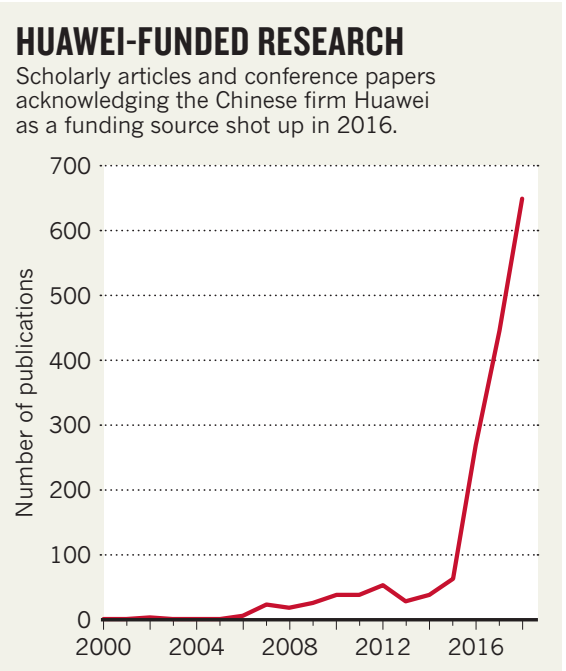

Shenzhen - has been under mounting scrutiny from international governments. Several countries have raised security concerns over its devices and over the company's involvement in developing their telecommunications networks.

The US charges against Huawei include theft of trade secrets, violations of economic sanctions, wire fraud and obstruction of justice.

In a statement published on its website, Huawei said it was "disappointed" to learn of the indictments, which includes individual charges against the firm's chief financial officer, Wanzhou Meng.

It added: "The Company denies that it or its subsidiary or affiliate have committed any of the asserted violations of U.S. law set forth in each of the indictments, is not aware of any wrongdoing by Ms. Meng, and believes the 
U.S. courts will ultimately reach the same conclusion." (Huawei did not respond to Nature's request for comment.)

Huawei reported spending 90 billion yuan (US $\$ 13.3$ billion) on research and development in 2017, including through partnerships with dozens of universities across the world (see 'Huawei-funded research').

In a letter to senior staff on 30 January, seen by Nature, Berkeley's vice-chancellor for research, Randy Katz, said that, effective immediately, the university would not enter into or discuss new research collaborations with Huawei, or seek or accept new research gifts from the firm, pending a ruling on the charges.
"UC Berkeley holds its research partners to the highest possible standards of corporate conduct, and the severity of these accusations raises questions and concerns that only our judicial system can address," Katz said in the letter.

Huawei and a US subsidiary, FutureWei, contribute to five research programmes, amounting to about $\$ 7.8$ million in funding over the past 2 years, says a spokesperson for the university. The moratorium does not apply to existing agreements for research already under way, Katz wrote.

The university says that none of the work involves sensitive technological secrets or knowledge, and that it does not grant the firm unique or exclusive rights to intellectual property from the research. As with all research at the university since the 1930s, the results are shared openly, adds the spokesperson.

The University of Texas at Austin - where Huawei has supported several research projects - says that it already treats Huawei as a 'sensitive entity'. The label means that the firm poses elevated information-security and export risks, and special guidelines govern researchers' interactions with the company.

A spokesperson for the University of Texas at Austin says that it will decide on how to move forward as quickly as possible

\section{The 'replicator' prints 3D objects from scratch}

\section{Printer creates whole structures all at once by projecting light into a resin that solidifies.}

\section{BY DAVIDE CASTELVECCHI}

$\mathrm{T}$ They nicknamed it the 'replicator' - in homage to machines in the Star Trek saga that can make nearly any inanimate object materialize.

Researchers in California have unveiled a 3D printer that creates an entire object in one go, rather than building it layer by layer as typical additive-manufacturing devices do - bringing science fiction a step closer to reality. "This is an exciting advancement to rapidly prototype fairly small and transparent parts," says Joseph DeSimone, a chemist at the University of North Carolina at Chapel Hill.

The device, described on 31 January in Science, works like a computed tomography (CT) scan in reverse, explains Hayden Taylor, an electrical engineer at the University of California, Berkeley, who was part of the team that devised the replicator. In CT machines, an X-ray tube rotates around the patient, taking multiple images of the body's innards. Then, a computer uses the projections to reconstruct a $3 \mathrm{D}$ picture.

The team realized that this process could be reversed: given a computer model of a 3D object, the researchers calculated what the structure would look like from many different angles, and then fed the resulting $2 \mathrm{D}$ images into an ordinary slide projector. The projector cast the images into a cylindrical container filled with liquid acrylate, a type of synthetic resin (B. E. Kelly et al. Science http://doi.org/ cz8v; 2019).

As the projector cycles through the images, which cover all 360 degrees, the container rotates by a corresponding angle. "As the

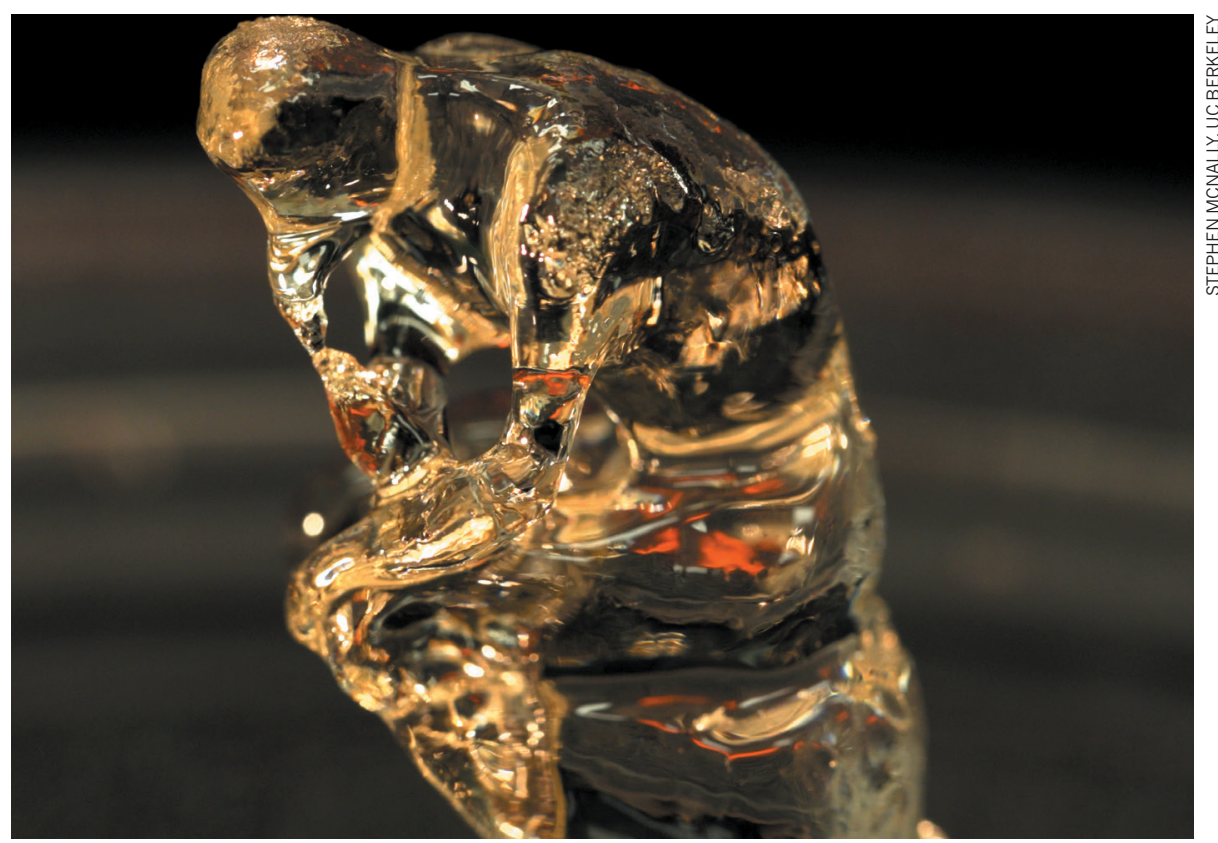

Think you know 3D printing? Think again.

volume rotates, the amount of light received by any point can be independently controlled," says Taylor. "Where the total amount exceeds a certain value, the liquid will become solid."

This is because a chemical in the resin absorbs photons and, once it reaches a certain threshold, the acrylate undergoes polymerization - the resin molecules link together into chains to make a solid plastic.

The exposure process takes about two minutes for an object a few centimetres across. The remaining liquid is then removed, leaving behind the solid 3D object. The team recreated a version of Auguste Rodin's sculpture The Thinker a few centimetres tall.

The process is more flexible than conventional 3D printing, Taylor says; for example, it can create objects that enclose existing ones. The resulting structures also have smoother surfaces than can be achieved with typical 3D printers, which could be helpful for manufacturing optical components. The scientists suggest that the method could be used for printing medical components. 